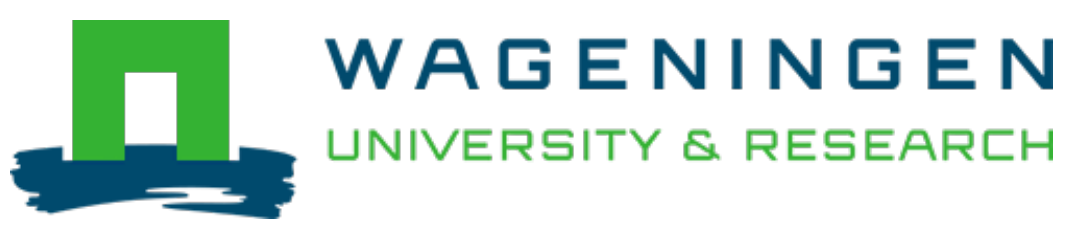

\title{
In vitro digestion enhances anti-adhesion effect of tempe and tofu against Escherichia coli
}

\author{
Letters in Applied Microbiology \\ Mo, H.; Yang Zhu, Yang; Nout, M.J.R. \\ https://doi.org/10.1111/j.1472-765X.2011.03189.x
}

This publication is made publicly available in the institutional repository of Wageningen University and Research, under the terms of article $25 \mathrm{fa}$ of the Dutch Copyright Act, also known as the Amendment Taverne. This has been done with explicit consent by the author.

Article 25 fa states that the author of a short scientific work funded either wholly or partially by Dutch public funds is entitled to make that work publicly available for no consideration following a reasonable period of time after the work was first published, provided that clear reference is made to the source of the first publication of the work.

This publication is distributed under The Association of Universities in the Netherlands (VSNU) 'Article $25 \mathrm{fa}$ implementation' project. In this project research outputs of researchers employed by Dutch Universities that comply with the legal requirements of Article $25 \mathrm{fa}$ of the Dutch Copyright Act are distributed online and free of cost or other barriers in institutional repositories. Research outputs are distributed six months after their first online publication in the original published version and with proper attribution to the source of the original publication.

You are permitted to download and use the publication for personal purposes. All rights remain with the author(s) and / or copyright owner(s) of this work. Any use of the publication or parts of it other than authorised under article $25 \mathrm{fa}$ of the Dutch Copyright act is prohibited. Wageningen University \& Research and the author(s) of this publication shall not be held responsible or liable for any damages resulting from your (re)use of this publication.

For questions regarding the public availability of this publication please contact openscience.library@wur.nl 


\author{
NOTE TO THE EDITOR
}

\title{
In vitro digestion enhances anti-adhesion effect of tempe and tofu against Escherichia coli
}

\author{
H. Mo ${ }^{1,2}$, Y. Zhu ${ }^{3}$ and M.J.R. Nout ${ }^{2}$ \\ 1 Department of Food Science, Henan Institute of Science and Technology, Xinxiang, Henan Province, China \\ 2 Laboratory of Food Microbiology, Wageningen University, Wageningen, the Netherlands \\ 3 Bioprocess Technology, Wageningen University, Wageningen, the Netherlands
}

\section{Keywords}

antimicrobials, bioprocessing, E. coli (all potentially pathogenic types), fermentation, fermented foods.

\section{Correspondence \\ M.J. Rob Nout, Laboratory of Food Microbiology, Wageningen University, Bomenweg 2, 6703 HD Wageningen, the Netherlands. \\ E-mail: rob.nout@wur.nl}

2011/1786: received 18 October 2011, revised 16 November 2011 and accepted 25 November 2011

doi:10.1111/j.1472-765X.2011.03189.x

\begin{abstract}
Aims: Enterotoxigenic Escherichia coli is one of the main pathogenic bacteria causing diarrhoea. Earlier studies have shown that tempe-a fungal fermented soya food-has anti-adhesive activity against $E$. coli in vitro. Our aims were to challenge the anti-adhesive activity under gastro-intestinal conditions and to assess the activity of the nonfermented soya product tofu.

Methods and results: In this study, we compared the anti-adhesive activity of two major soya bean products, tempe and tofu, and their ileum efflux after transit through a dynamic gastrointestinal system simulating digestion in the human stomach and small intestine. The results showed that both tempe and tofu have an anti-adhesive activity against $E$. coli in vitro. Tempe and tofu, after digestion through the stomach and small intestine, have even higher anti-E. coli adhesive activity.

Conclusions: In addition to the proven in-vivo activity of tempe, this confirms the potential antidiarrhoeal effect of both the soya products tempe and tofu.

Significance and Impact of the Study: As tofu has a much greater circle of consumers, this finding is relevant for the health of a large part of the world's population.
\end{abstract}

Diarrhoea is a widespread disease in developing countries, where 4.9 per 1000 children under the age of 5 years die from diarrhoea every year (Kosek et al. 2003). Enterotoxigenic Escherichia coli is one of the major pathogens associated with infant diarrhoea (Roubos-van den Hil et al. 2009). Antisecretory agents to treat diarrhoea have serious side effects and can impair the central nervous system. Therefore, natural compounds that provide substantial benefit combined with a safety and selectivity of action should be considered as a part of the diarrhoea treatment (Bhan 2000).

Extracts from tempe, an indigenously fermented soya bean product in some oriental countries, show a strong bioactivity in vitro by reducing the adhesion of enterotoxigenic diarrhoea-causing E. coli to animal and human intestinal cells (Kiers et al. 2002; Roubos-van den Hil et al. 2009).
Extracts of raw, soaked and cooked soya beans can reduce E. coli adhesion in vitro, although the effect was lower than that of tempe extracts (Roubos-van den Hil et al. 2009). Therefore, we assume that other soya products such as tofu could have a similar function. Tofu is one of the most popular soya bean products consumed in Asia (Quak and Tan 1998).

However, any bioactive components, when administrated orally, must withstand the harsh $\mathrm{pH}$ conditions in the stomach and hydrolytic enzymes and bile in the small intestine.

We used a dynamic computer-controlled gastrointestinal system that simulates the human digestion tract to test whether tempe and tofu retain their anti-adhesion effect against E. coli after transit through the digestion tract. In addition, we compared the in vitro anti-adhesion ability of tempe and tofu that had been prepared under 
different soaking conditions and with different fermentation starter cultures to study the effect of processing methods.

Tempe was prepared according to the procedure described previously (Roubos-van den Hil et al. 2009). Beans were soaked in $30^{\circ} \mathrm{C}$ tap water or acidified water for $24 \mathrm{~h}$ and then cooked for $20 \mathrm{~min}$. To evaluate the effects of processing parameters on E. coli adhesion, we selected two different soaking conditions: soaked in (i) tap water at neutral $\mathrm{pH}$ and (ii) in acidified water with lactic acid bacteria Lactobacillus plantarum (LU 852) at an inoculation level of $10^{6} \mathrm{CFU} \mathrm{ml}^{-1}$. After cooling, the beans were inoculated with the starter culture and incubated at $30^{\circ} \mathrm{C}$ for $48 \mathrm{~h}$. Two starter cultures were used for the fungal fermentation of tempe, viz. a commercial mixed starter (Raprima, Semarang, Indonesia) and a pure culture of Rhizopus microsporus var. microsporus (LU573) provided by the Laboratory of Food Microbiology, Wageningen University. Fresh tempe was cooked in a microwave for $5 \mathrm{~min}$ before the digestion experiment.

Soya beans were soaked in tap water at $20^{\circ} \mathrm{C}$ overnight, milled with water to a milky slurry (ratio of bean dry weight to water $=1: 8$ ). The slurry was heated to $95-100^{\circ} \mathrm{C}$ for $4 \mathrm{~min}$ and filtered through a cheese cloth to separate the soya milk. Coagulation was done at 70$80^{\circ} \mathrm{C}$ by adding calcium sulfate $(3.0 \%$ of the soya bean dry weight) under agitation. Then, the mixture was left for $10-15 \mathrm{~min}$ to complete the coagulation. The coagulated curd was pressed to remove excess water. Finally, a soft, cake-like tofu was formed. The fresh tofu was cooked in a microwave for $5 \mathrm{~min}$ before the digestion experiment.

The dynamic computer-controlled gastrointestinal system simulating the human stomach and small intestine has been described elsewhere (Minekus et al. 1995). Tempe or tofu was put into the stomach compartment with artificial saliva, amylase and water. In the jejunum and ileum compartments, bioaccessible nutrients went through the prefilter and semi-permeable membrane and were collected. The nondigested compounds were collected as ileum efflux at the end of the ileum compartment. The ileum efflux samples were similar to the chyme entering the colon, and we used this efflux to test the in vitro anti-adhesion activity.

All tempe and tofu products, as well as tempe and tofu ileum efflux, were freeze-dried (GR Instruments; Wijk bij Duurstede, Netherlands), then ground (Ultra Centrifugal Mill ZM 200; Retsch GmbH, Haan, Germany), sieved through a $0 \cdot 5-\mathrm{mm}$ sieve and stored at $-20^{\circ} \mathrm{C}$.

An accurately weighed $1 \mathrm{~g}$ of dried powder was dissolved in $30 \mathrm{ml}$ distilled water and stirred for $1 \mathrm{~h}$ at room temperature. After centrifugation $\left(2600 \mathrm{~g}\right.$ at $4^{\circ} \mathrm{C}$ for $15 \mathrm{~min}$ ), the supernatant was collected and the pellets were re-suspended with $10 \mathrm{ml}$ distilled water and centri- fuged again. This re-extraction step was repeated twice. All supernatants were collected and freeze-dried for the anti-adhesion experiments.

Enterotoxigenic E. coli (O149: K88 ${ }^{\mathrm{ac}}$ ) strain ID1000 (ETEC K88; source: Animal Science Group, Wageningen UR, Lelystad, Netherlands) was used as the experimental strain and nonadhering E. coli (O149:K91) strain ID1084 (source: Animal Science Group, Wageningen UR, Lelystad, Netherlands) as a negative control. Effect of soya bean extracts and ileum efflux on the adhesive ability of E. coli to piglet intestinal brush border cells was measured according to the method described previously (Roubosvan den Hil et al. 2009). To detect concentration effects, bean, tempe or tofu extracts and ileum efflux were added at $1,2.5$ and $10 \mathrm{~g} \mathrm{l}^{-1}$ concentrations in phosphate-buffered saline. These concentrations were physiologically relevant, considering a serving size of $100 \mathrm{~g}$ of soya bean product of which at least $30 \%$ of dry matter is solubilized by digestion; in the intestinal tract, this would be diluted to concentrations of at least $10 \mathrm{~g} \mathrm{l}^{-1}$ (Kiers et al. 2000).

Figure 1 shows the anti-adhesion effect of cooked soya bean, tempe (raw or cooked), tofu (raw or cooked) and tempe and tofu after the transit through the in vitro gastrointestinal system (ileum effluent samples) on E. coli K88 to piglet intestinal brush border cells.

Tofu also had anti-adhesive activity, although lower than that of tempe. After the tempe and tofu transit through the gastrointestinal system, the anti-adhesion activity of ileum efflux did not only exist, but was even higher than undigested tempe or tofu. At the lowest level of $1 \mathrm{~g} \mathrm{l}^{-1}$, tempe and tofu ileum efflux still had significant inhibition against E. coli adhesion. The anti-adhesion effect is dose dependent, that is, the higher the concentration, the higher the anti-adhesion effect.

Tempe, either raw or cooked, had anti-adhesive activity against E. coli K88 to piglet intestinal brush border cells. After cooking, the activity decreased. Small differences in anti-adhesion activity were observed when tempe was produced under different soaking conditions and fermented with different starter cultures. Therefore, we chose tempe made by acidified soaking and inoculated with pure Rhizopus microsporus (LU573) (highest folate and vitamin B12 content, data not shown here) to compare the anti-adhesive activity with tofu to study the antiadhesion activity after in vitro digestion.

Adhesion is expressed relative to the control as $100 \%$ without addition of the testing extract. The negative control represents the adhesion of a nonadhering strain E. coli K91. Tempe made by different processing methods did not have significantly different effects on E. coli adhesion. The anti-adhesion effect increased when the concentration of the extract increased. The anti-adhesive effect was dose dependent $(P<0 \cdot 05)$. 


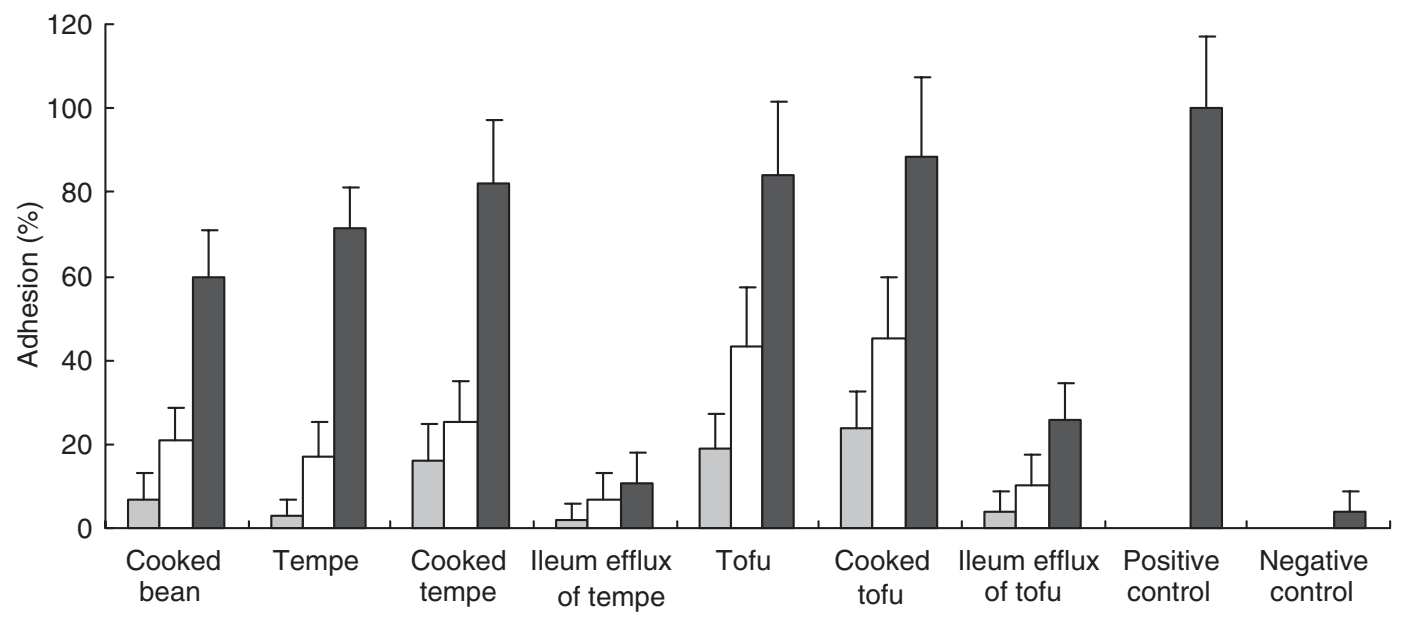

Figure 1 Adhesion of Escherichia coli $\mathrm{K} 88$ to piglet intestinal brush border cells. Extracts were added at three concentrations $1 \mathrm{~g} \mathrm{I}^{-1}$ (black bar), $2.5 \mathrm{~g} \mathrm{I}^{-1}$ (white bar) and $10 \mathrm{~g} \mathrm{I}^{-1}$ (grey bar). Positive control was adhesion of E. coli K88 to piglet intestinal brush border cells without soya bean extract. Negative control used no-adhesive E. coli K91 to piglet intestinal brush border cells.

We suggest that the enhanced anti-adhesion effect of tempe and tofu after the in vitro digestion was caused by the absorption of low-molecular size digestion products in the small intestine. Consequently, it caused the accumulation of larger molecules in the efflux, among which the anti-adhesion bioactive component (Roubos-van den Hil et al. 2010) was present.

Soya bean and its products tempe and tofu all were shown to exhibit anti-adhesive activity against E. coli in vitro. Tempe made with different processing methods did not differ in anti-adhesion activity. The anti-adhesion activity is retained and even enhanced after the tempe and tofu have passed through the gastrointestinal system where they could withstand the harsh $\mathrm{pH}$ in the stomach and pancreatic secretions and bile in the small intestine. This underpins in-vivo observations (Kiers et al. 2003) showing that tempe has a protective function against diarrhoea-causing E. coli. Based on the in vitro data presented in this note, we hypothesize that tofu has a similar effect in vivo.

\section{Acknowledgements}

We thank Graduate School VLAG of Wageningen University for the research grant to H.M., and Dr Petra Roubos of Nutreco Boxmeer for providing the experimental materials and protocols.

\section{References}

Bhan, M.K. (2000) Current and future management of childhood diarrhoea. Int J Antimicrob Agents 14, 71-73.
Kiers, J.L., Nout, M.J.R. and Rombouts, F.M. (2000) In vitro digestibility of processed and fermented soya bean, cowpea and maize. J Sci Food Agric 80, 1325-1331.

Kiers, J.L., Nout, M.J.R., Rombouts, F.M., Nabuurs, M.J.A. and van der Meulen, J. (2002) Inhibition of adhesion of enterotoxigenic Escherichia coli K88 by soya bean tempe. Lett Appl Microbiol 35, 311-315.

Kiers, J.L., Meijer, J.C., Nout, M.J.R., Rombouts, F.M., Nabuurs, M.J.A. and Van der Meulen, J. (2003) Effect of fermented soya beans on diarrhoea and feed efficiency in weaned piglets. J Appl Microbiol 95, 545-552.

Kosek, M., Bern, C. and Guerrant, R.L. (2003) The global burden of diarrhoeal disease, as estimated from studies published between 1992 and 2000. Bull World Health Org 81, 197-204.

Minekus, M., Marteau, P., Havenaar, R. and Huis in 't Velt, J. (1995) A multicompartmental dynamic computer-controlled model simulating the stomach and small intestine. ATLA Alt Lab Anim 23, 197-209.

Quak, S.H. and Tan, S.P. (1998) Use of soy-protein formulas and soyfood for feeding infants and children in Asia. Am J Clin Nutr 68, 1444S-1446S.

Roubos-van den Hil, P.J., Nout, M.J.R., Beumer, R.R., van der Meulen, J. and Zwietering, M.H. (2009) Fermented soya bean (tempe) extracts reduce adhesion of enterotoxigenic Escherichia coli to intestinal epithelial cells. J Appl Microbiol 106, 1013-1021.

Roubos-van den Hil, P.J., Schols, H.A., Nout, M.J.R., Zwietering, M.H. and Gruppen, H. (2010) First characterization of bioactive components in soybean tempe that protect human and animal intestinal cells against enterotoxigenic Escherichia coli (ETEC) infection. J Agric Food Chem 58, 7649-7656. 